\title{
An Interview With Alan Dugan
}

\section{Michael Ryan}

Int.: Your poems began appearing in magazines in 1945, yet your first book, Poems 1, wasn't published until 1961. Did you plan to wait that long to come out with a book?

Dugan: No, I wasn't planning at all. Although I began writing at 17, for a long time I wrote very few successful poems, according to my own approximation. I didn't begin to write poems I thought were tolerable until my middle thirties. So contrary to the general rule, I didn't start young, although I started writing young.

Int.: Were there special difficulties involved with beginning to write when the "giants" were dominating the literary scene? How did you deal with Eliot, for example?

Dugan: I discovered Eliot and William Carlos Williams on just about the same day in the New York Public Library when I was in high school, and those two men were the poles of influence in my own early experimentations with form-Eliot, the expatriate, a very learned poet working intensely in terms of a literary tradition, and Williams, on the other hand, trying to write spoken American. Those two polar aesthetics were part of the tension that led me to go on writing, and in later days, both of them were extremely helpful to me-Williams giving advice and Eliot trying to to get me published in England.

At the same time, however, I was relatively fortunate in getting mixed up with a bunch of expatriate Italian surrealists at the first college I went to, Queen's College in New York. Also, when I went into the army shortly after that, I fell under the influence of Karl Shapiro when he was writing his most formal verse. The combination of the two helped burn the influence of Eliot and Williams out of my soul. I did try generally to avoid English Departments when I was in college. I was more interested in anthropology, economics, and history.

Int.: Was the atmosphere for writing different at that time?

Dugan: Yes. The Forties was of course the time of "New Criticism" or the remains of it, so that when I was in high school and in college for a short while before joining the army there was an overwhelming theoretical presence which said that every word in a poem had to have a precise defensible function or else the poem failed. A lot of poets were writing more for the critics than for an audience outside of the profession. My association with those surrealists was a liberation for me from the 
American and English academy, although I did attempt to write formal witty verse for awhile under Karl Shapiro and failed completely. But the truth is that much of my work is secretly formal. I'm not an explicit formalist in making external forms that call for counting and rhyming, but a lot of my work does count in a way and does rhyme although not at the ends of lines.

Int: Were you writing at that time out of your sense of sound as the primary method of determining word-choice or dealing with the material of a poem?

Dugan: For most of my life my position has been that a poem has to be oral and aural, but that by no means is the only consideration. The poem I want to write should have a sonic solidity to it, should have some formal construction however hidden, and it should also say something. Just as I'm a secret formalist, I'm a secret believer in content.

Int.: One of the poems that was most popular with the "New Critics" was the metaphysical or meditative poem, and I think many of your poems, if you have to categorize them, are meditative.

Dugan: That's largely true, as a matter of fact. My poems often tend to deal in metaphysical conceits. They're meditative, moral, they tend to be political, and they tend to try to make statements about the nature of the human condition in the universe. To that extent, I have a philosophical bias without a philosophy.

Int.: Essentially the reason I was first attracted to your poems is because the voice or vision or whatever you want to call it is characterized by an unremitting self-irony, a process of stripping away illusion until nothing is left and then laughing at it. Does that strike you as an accurate description?

Dugan: I think so. It goes back to the fact that I was a late starter, and the more romantic verse I wrote as a young man turned out to be no good according to my own opinion so I destroyed it. I became appalled at my own sentimentality and tried to strip everything to the bone. To rephrase my answer to your last question, from my point of view, my aesthetic if I really have one, a poem should have sensual value, but I see no reason for a poet to avoid the fact that he has an intelligence, because we are all either blessed or cursed with intelligence. I think that poetry should be an expression of the whole person, not necessarily for egoistic purposes but in order to point out the fact of the human condition.

Int.: Do you think that your poems refer more to a conscious conceptual process than other poems that you know?

Dugan: In my own case, and I think in the case of a majority of poets, one begins with a gift phrase or a gift of words which comes out of the unconscious. That has rarely been sufficient for me. I've rarely gotten a poem in one or two sittings. I involve myself in a process of revision, and it's when I revise that my conscious intelligence joins the conversation. So it's my intention to make a poem of an internal conversation between various parts of myself, which are sometimes unconscious, sometimes semi- 
conscious, sometimes speculative in conscious thought. Again, I think it's more or less a valid way of proceeding because it indicates something about the nature of human beings in general. Many people, many colleagues, would disagree with my position very strongly. Some of them think that anything one writes in a moment of passion must be correct because it's a passionate statement. But that begs the question, because who is it passionate for? Any art is absolutely social. It involves communication first between the selves of the artist and also between the artist and some audience, some second person. I can't write a poem to the stars or trees; it has to be involved with other people because poetry is a matter of language, and local language at that.

Int.: At the moment of writing, though, you obviously don't postulate a second person, do you? Isn't the reader inside you?

Dugan: It works both ways. The artist is social in the primary sense of the individual, insofar as any individual has various aspects of his or her character which may or may not be aware of each other, and the artist is social insofar as he has a compulsion to externalize his work. Even the most private artists write for someone besides themselves. Emily Dickinson is the classic example, sending her poems to that creep Higginson.

Int.: Can you connect this concern for locating yourself in a social way to the sense of location that operates in your poems?

Dugan: I think poetry has to be local because of the limitations of the language. Every poet writes in a particular dialect of a local language. I have to write in American English because I don't understand any other language thoroughly enough to write in it, and I'm limited to a specific variety of American English, located on the East Coast generally situated around New York City. If I move away from that, the language of my childhood, I find myself going false, making incorrect statements and sentimentalities, so I try to write poems which are specifically located in terms of place and language. Even that works out badly once in a while, because I tend to write narrative and dramatic poems which can easily become fictional or melodramatic.

Int.: Are you writing the same kind of poem now as in your first three books? Dugan: I'm afraid so. After the publication of Poems 3, I just about shut up for several years because I couldn't stand the sound of my own voice. I thought I was imitating myself. I tried to break away from that, but wasn't too successful. I'm making a new book now which should be out on the Spring list. It's roughly the same, without too much difference in language or approach.

Int: In 1961, you won the Yale Series, the National Book Award, the Pulitzer Prize, and a Prix de Rome within a period of a few months, after writing seriously for almost twenty years. How did that affect you?

Dugan: It changed my life completely, because until then I had been working for a long time at a number of ordinary jobs. I put in my year in advertising, for a number of years I ran a printing and greeting card busi- 
ness, and at the time I won the prizes I was working as a model maker in a plastic shop. So, in terms of money, the prizes and giving readings freed me completely from business life and working from nine to five. My wife and I just took off for Europe for a few years, and I haven't done an honest day's work ever since.

Int.: Did it affect your work?

Dugan: Yes, probably for the worse, because I got away from the realities of American life, which is business. You know the old Calvin Coolidge line "The business of America is business." I don't regret those years, because unless you run a business, you really get no visceral insight into the nature of American society and culture. Because that is the basic thing about America-jobs, working-and once you step out of that, you lose a certain degree of contact. Not that I'd take a lousy job again, but my getting the small amount of recognition that a poet gets involved a loss of continuity, of a certain amount of wisdom and insight about the American beast, the American economy.

Int.: Is that one of the reasons you emphasize your use of the American, as opposed to the English, language?

Dugan: Yes, besides which it's just about impossible to learn English. It's one of their popular games, like soccer. Everyone can place everyone else in terms of class and locale. If you spend any time in England, you can see Americans trying to learn how to speak it; these people are figures of fun to the English, who can place them immediately. American and English are two different languages, especially the spoken languages which are entirely different in rhythms, grammar, the manner of speaking. Also, you have to learn a whole new vocabulary in order to survive.

Int.: I guess the difference could also be seen from the other side in terms of the American idiom, which perhaps relates back to your description of the atmosphere of the Forties and Fifties. Many poets were writing a formal verse in terms of diction, as well as just in terms of metrics and rhyme schemes.

Dugan: That's right. Then the academic American poets used a very formal written language, without too much emphasis on its oral and aural quality. Nevertheless, these poets were absolutely recognizable as American writers. That's one of the reasons that the English poets imitate us, and we don't imitate the English, because American verse has more vigor and particularity.

Int.: Is that because of the idioms?

Dugin: It's because we aren't so class-bound as English intellectuals are. When a classy Englishman from one of the big universities tries to write popular English speech of a certain locality, it sounds like genre poetry. Whereas American poets have less difficulty in this regard because we're less well-educated, much less well-educated.

Int.: Do you have any notion of literary history that makes any sense of the movement in this country from 1950 to now? It seems that when critics 
talk about literary history and construct their fictions about it, they can use thirty or fifty or seventy year periods and make some reasonably intelligent generalizations. Maybe it's just because we're alive right now, but it seems to me that the fashions, the modes, are changing more like every three or five years.

Dugan: I think there are two interrelated directions involved in what is happening today: the popularity of what I call neo-surrealism, and an impetus toward great length in poems and absolute looseness in structure. On the other hand, neither of these directions reflects the whole picture. I think the situation in the United States of America and England is that we're all coming after the great giants-Eliot, Pound, Williams, Marianne Moore, and the rest of them. So that in the United States of America there's a group of forty or fifty extremely interesting poets right now, but I think that none of us are really large-scale artists in the way they were. They made enormous breakthroughs in the first years of the century, and what's going on is that all of us are working out variations of those breakthroughs.

I think because of that, and because of the technological development of American society, there is this reflection of rapid change in the modes and fashions of art. American culture is in a state of extreme flux, technological change occurs with such speed, and with the ease of publication, poetry becomes like Seventh Avenue fashions-there has to be something new every year. You can say, after Lukács, that art and literature respond to the social and economic conditions which produce it, but it's also true to say that art has a life of its own because it has its own history. However, both in our time seem to coincide. In my experience, at some point after burning out the influences of Eliot and Williams, I realized that because we live in a mass culture, each professional artist is bound to be as individuated as possible, to find his own precise voice. That's a sensible contradiction, isn't it: mass culture and individuated artists.

Int.: You mentioned in another context that you discovered that voice in your middle thirties. Do you think your discovering it was a matter of coming upon material that allowed you to do so, and was it a psychic or formal process as well?

Dugan: I have no clear idea. Perhaps in my case it was a matter of getting as far away from academia as possible and just being mixed up in the rat race of New York, trying to make a buck and survive. It's true, though, that now any interesting poet can be recognized after reading a few lines. In the old days, in a feudal or aristocratic society when a poet was a court entertainer, poetry could go on for generations with minor variations on the same theme and the individual voices were indistinguishable.

Int.: How about individual poems? Can you describe how you came to write "Love Song: I and Thou"? 
Dugan: For that particular poem, I got a gift from a passionate experience of building something, being annoyed with it, and wondering about the nature of family life. I got all the gift phrases and words out of experiencing anger and love in this way, and put them aside when I couldn't get anymore. I came back later and revised it until I thought I had a form or anti-form that related to the intent of the work, which is my feeling that a human being has an innate necessity to create some sort of orderly construct for his or her life and how that construct inevitably fails because of our animal inefficiency and mortality. That's what I wanted to state in the poem. I try to make the form of a poem relate in some way to my notions of questions about human life in the universe-are things orderly or disorderly, do we live in a state of flux in which temporary orders are destroyed by change, and the rest of it. It does seem to me that any family relationship, any loving relationship, demands a certain construct no matter how ephemeral. Screwing is a physical construct in which either one or both of the pair achieve satisfaction, and in that sense it's a temporary construct which evaporates all too quickly.

Int.: Do you think that's a good metaphor for writing, screwing?

Dugan: That's a good question. Without trying to answer it, I would say that I don't think an artist's sublimation through his art has anything to do with his degree of sexuality. There's an infinite relation between sexuality and the compulsion to produce works of art, but it doesn't necessarily connect with the sexual activity of the artist. I've come across some poets who have ten kids and any number of mistresses, and I've come across some poets who have never touched a woman or a man in his or her life. And they both can be equally good as artists.

Int.: Do you see yourself as a compulsive person? Is that an answer to the old question of why you write poems, because you're compelled to?

Dugan: Certainly I'm compulsive. I'm not entirely sure that an artist works in terms of a childhood trauma, in a competition with his or her father, but it's a classic theory and I'm impressed with the force of it. I remember my father reciting poems at family gatherings, Rudyard Kipling and the like, and something in me at that time resolved to either equal him or better him, preferably to better him. He died about the time I was thirty, at a time when you know you have to do something to become a man.

Int.: Do you use autobiographical material in your poems?

Dugan: Sometimes I do, but more often the poems in which I use the word "I" do not necessarily relate to my own experiences. They are invented " $I$ "'s, and invented experiences also.

Int.: Many of your poems use the war situation in them. At some point in your life you must have found that to be an appropriate location for a poem.

Dugan: World War II was crucial to my own life, or at least to the 3\% years of it I spent in the Air Force. I was a premature anti-fascist, a mature 
anti-fascist, and now I'm a post-mature anti-fascist, as the joke goes. Being in the army was very instructive about my own country, America, because armies are exact reflections of the culture which produces them; the social norms, the rules, are the same as in civilian life, only they're reinforced very punitively. As a kid enlisting to fight the Nazis, it was interesting to realize that the United States army was the first enemy, and the Germans were the second enemy. The whole experience served to reinforce my historical curiosity. One of the things I think about constantly is the relation between the old dynasties and the nature of imperialisms, so it's given me a way to play back and forth with time. Given that historical bias, I think I can talk about modern armies accurately in terms of a Roman army or Athenian army or Spartan army. And it's very useful to me to be able to acknowledge the fact that there is a past, because in the United States of America, by its nature, the past is in a constant process of destruction. Most Americans pretend there isn't a past at all.

Int.: What did you do in the Air Force?

Dugan: I spent most of my time trying to survive. Actually I worked on ground crews-a nice peaceful boring existence-except for the good fun provided by our enemies, the officers, of course. I have found it useful, though, also because I'm an opponent of the United States' unconstitutional military involvement in Vietnam. I've read poems for ten years or so at anti-war occasions, and it's been helpful to be able to talk about the army from the inside.

Int.: I like to believe that poems are made in some sense out of memory: memory of language, of sensual details, of specific events, etc. Could that be why the war shows up in many of your poems?

Dugan: Certainly. The United States military is a real shock for any young man who has led a rather sheltered existence. Talking about memory, Stephen Spender said that poets don't have to have good memories, but they must have selective memories. There's a compulsion operating in any artist that makes him feel it is necessary to make things, and what he finally writes down are those things which come out of a compulsively selective memory. The word compulsion is a nice substitute for the word creativity.

Int: How about your method of working? Do you keep a notebook?

Dugan: Yes, I work in and out of notebooks-keeping the gifts, taking a poem out of a notebook and retranscribing it in order to see what the poem wants to be. I should rephrase something I said before: the process of revision for me is not that conscious in terms of conscious decisions, insofar as that implies attempting to apply an intellectual process to an unconscious or emotional gift. It's more complicated than that. What I do when I succeed is dream my way back into the poem, into the way the poem itself wants to be. I try not to expose the impulse to con- 
scious or intellectual form, but to keep the mediating aspects of dreaming at work with the partially intellectual process of revision.

Int.: You say what the poem itself wants to be-do you feel that you are placed in the poem in such a way that you speak from the poem rather than through the poem?

Dugan: It varies. When I'm successful, I find the poem will come out saying something that I didn't previously know, believe, or had intellectually agreed with. I have the notion, although I succeed only infrequently, that there is some construct that wants to surface, and if I follow the process, both by dreaming and intellectual work, then the poem will result in a surprise, an emotional charge. It will say neither my conscious intention, nor will it say what the unconscious speaker wanted to say, but those several individuals will be blended in a common voice. There's always that need for self-exposure in art, even in dealing with the most formal themes. The irony is that the artist feels shame about it and perhaps realizes at the same time that it doesn't matter because nobody gives a damn. Unless you get into difficulties for being radical, politically or sexually, and somebody busts you for it.

Int.: How many drafts do you usually do?

Dugan: Sometimes I can get away with three or four, sometimes I have to write as many as twenty-five or thirty. The formalist says that you must consider the poem perfect because you leave it and, as Valery says, you abandon it. In my opinion, it's always possible to further transform or make variations on a poem, and the fact of finishing is all too often an act of accident, fatigue, publication date, or what have you.

Int.: Do you find yourself writing about the same subjects now in the fourth book?

Dugan: Yes. As I said before, I'm still doing business at the same old standlove, work, war, death, what the world is like outside this window tonight. 